\title{
Practical considerations of dietary therapies for epilepsy in adults
}

\author{
Neha Kaul ${ }^{1,2,3,4^{*}}$, John-Paul Nicolo ${ }^{3,4}$, Terence J. O'Brien ${ }^{3,4}$ and Patrick Kwan ${ }^{3,4,5}$
}

\begin{abstract}
Despite the increasing number of anti-seizure medications becoming available, the proportion of patients with drug-resistant epilepsy remains unchanged. Dietary therapy for epilepsy is well-established practice in paediatric care, but relatively underutilised in adults. Recently, international recommendations have been published to guide the treatment of adults receiving dietary therapy for epilepsy.

This review focuses on the specific aspects of care unique to the management of adults receiving dietary therapy for epilepsy, including patient selection, diet composition, initiation, monitoring and cessation of dietary treatment. We emphasise the need for a multidisciplinary team approach with appropriately trained neurologists and dietitians to provide holistic care while the patients are receiving dietary therapy. Future research should focus on the optimal diet composition and meeting the psychosocial needs of adults with epilepsy to maximise efficacy and adherence to dietary treatment.
\end{abstract}

Keywords: Ketogenic diet, Epilepsy, Diet, Drug-resistant epilepsy, Nutrition

\section{Background}

Epilepsy is one of the most prevalent, serious neurological disorders, affecting approximately 50 million people worldwide. Epilepsy is associated with poorer health outcomes, including not only physical disability, but significant psychological and emotional burden leading to poor quality of life [1]. The underlying causes of epilepsy can be genetic, structural, metabolic, infectious, immune or in many cases the cause remains unknown [2].

For approximately $70 \%$ of people with epilepsy, seizures will be controlled with 1 or 2 anti-seizure medications [3]. Despite the growing number of anti-seizure medications that have become available over the past two decades, the proportion of people with drug-resistant epilepsy and uncontrolled seizures remains unchanged [4]. Non-drug treatment options for drug-resistant epilepsy may include surgery, neuromodulation and dietary therapy $[5,6]$.

\footnotetext{
* Correspondence: n.kaul@alfred.org.au

'Department of Nutrition and Dietetics, Alfred Hospital, 55 Commercial Road, Melbourne, VIC 3004, Australia

${ }^{2}$ Department of Allied Health (Clinical Nutrition), Royal Melbourne Hospital, Parkville, Australia

Full list of author information is available at the end of the article
}

Ketogenic diet therapy has been used for epilepsy treatment for over 100 years, traditionally in children. More recently, there have been an increasing number of trials investigating its efficacy in adults $[7,8]$. In 2020, the first international recommendations for the management of adults treated with ketogenic diet therapies were published [9].

The classical ketogenic diet is a very low carbohydrate, high fat diet, which is difficult for children and adults to comply with [10]. Over time, there has been development in variations of the classical ketogenic diet, including the modified Atkin's, modified ketogenic, medium chain triglyceride and low glycaemic index diets (Table 1) [8]. These less restrictive diets have fuelled further interest in the use of dietary treatments in adults with drug-resistant epilepsy in the context of a multifaceted approach to attaining better seizure control.

Dietary management of epilepsy has a number of advantages over adding multiple anti-seizure medications in patients with drug resistant epilepsy and uncontrolled seizures. Unlike anti-seizure drugs, dietary therapies are not associated with neurotoxic adverse effects, idiosyncratic reactions, or pharmacokinetic interactions through hepatic enzyme induction. Dietary therapies may have

(c) The Author(s). 2021 Open Access This article is licensed under a Creative Commons Attribution 4.0 International License, which permits use, sharing, adaptation, distribution and reproduction in any medium or format, as long as you give appropriate credit to the original author(s) and the source, provide a link to the Creative Commons licence, and indicate if changes were made. The images or other third party material in this article are included in the article's Creative Commons licence, unless indicated otherwise in a credit line to the material. If material is not included in the article's Creative Commons licence and your intended use is not permitted by statutory regulation or exceeds the permitted use, you will need to obtain permission directly from the copyright holder. To view a copy of this licence, visit http://creativecommons.org/licenses/by/4.0/. 
additional benefits, such as weight management and patient empowerment for self-management of chronic diseases.

In this review, we focus on the practical aspects specific to the use of dietary therapies for epilepsy in adults in the outpatient setting. Use of dietary therapies for emergency inpatient indications (e.g. status epilepticus) has been discussed elsewhere [11].

\section{Efficacy of dietary therapy for drug-resistant epilepsy in adults}

There have been a small number of published randomised controlled and prospective, open-label studies investigating the efficacy and tolerability of dietary therapy for drug-resistant epilepsy in adults published to date $[7,12]$. These studies vary in the dietary prescription used and duration of treatment. Response rate to dietary therapy, defined as $\geq 50 \%$ reduction from baseline ranged between 21 and $86 \%$, confounded by high drop-out rate and poor compliance with the dietary intervention. Adverse effects reported were rated as mild or moderate, namely weight loss, hyperlipaemia and gastrointestinal symptoms. The majority of adverse effects were transient and considered preventable or treatable, although they may have contributed to participant drop-out. The long-term effects on the development of cardiovascular disease require further investigation [13].

\section{The multidisciplinary dietary therapy team}

Essential to the dietary therapy team are dietitians and neurologists with experience in the management of dietary therapies for epilepsy. The neurologist is responsible for overseeing the overall epilepsy management plan, including assessing suitability, monitoring and evaluation of dietary therapy. The dietitian formulates the nutrition prescription and provides nutrition education on implementing and maintaining dietary therapy. The dietitian closely monitors the patient's nutritional status and makes adjustments to the nutrition plan as required to minimise adverse effects associated with the diet. The addition of trained multidisciplinary healthcare professionals further supports the diet program. Epilepsy nurses may provide additional training on completion of seizure diaries, ketone testing and coordinate patient investigations. The inclusion of a pharmacist in the dietary therapy team is beneficial in reviewing and minimising carbohydrate content of medications and drug-diet interactions. Some patients may also benefit from psychological support to assist with the transition onto dietary therapy and maintain adherence.

A centre-based guideline for the model of care for the diet program should be in place. Aspects of the model of care to consider include referral and treatment pathways, frequency and method of contact and frequency of pathology monitoring. Careful attention should be given to management of acute illness, hospital presentation, peri-operative and out-of-hours management [14]. Consultation with emergency, general medicine, surgery and intensive care unit departments may be required. In addition, adequate communication of dietary therapy plans should be provided to the patient's primary care physician and associated healthcare providers.

Dietary therapy most commonly is initiated in the outpatient setting; however the initiation protocol varies between centres [9]. Some centres have reported gradual introduction of the diet over days or weeks, whilst others report a more rapid transition depending on the individual patient's circumstances. Inpatient commencement of dietary therapy may be required in certain situations, where increased monitoring or complex, high intensity multidisciplinary support is required e.g. comorbid diabetes, oral feeding difficulties or gastrointestinal intolerance.

\section{Patient selection}

Generally speaking, dietary treatment can be considered for patients with drug-resistant epilepsy that is not amenable to epilepsy surgery. For patients diagnosed with glucose-transporter-1 or pyruvate dehydrogenase deficiency syndrome, dietary therapy is recommended as first-line treatment [15].

Patients should be evaluated for contraindications prior to commencing dietary therapy.

Fatty acid transport or oxidation disorders, disorders of carnitine metabolism and certain inherited errors of metabolism are absolute contraindications for dietary therapy [16]. The safety of dietary therapy for epilepsy during pregnancy and lactation is unknown. Data from animal studies of ketogenic diet exposure during pregnancy has shown harmful effects on maternal fertility and increased risk of ketoacidosis during lactation, as well as impaired foetal development $[17,18]$. Careful risk and benefit assessment and appropriate counselling should be provided to females of child-bearing potential.

Relative contraindications may include the presence of metabolic comorbidities such as diabetes mellitus, liver or renal disease, malnutrition, food allergies or intolerance, history of kidney stones and cardiovascular disease. Increased monitoring or modifications to the dietary prescription may be required for patients with these conditions.

There are limited data on the safety and efficacy of dietary therapy in the older adults. This age group is particularly susceptible to cognitive adverse effects of anti-seizure medications, drug-drug interactions, and may not be suitable candidates for epilepsy surgery due to comorbidities. Therefore, dietary therapy may have 
Table 1 Overview of dietary therapy for epilepsy prescription types

\section{Diet type}

Classical

ketogenic diet

\section{Overview}

Prescribed as a fixed ratio of grams of fat:non-fat e.g. 4:1

or 3:1.

All food and fluids must be weighed/measured and provided in the set ratio.

Modified

ketogenic diet
Prescribed as a daily dietary macronutrient distribution. Uses household measures and smartphone applications for monitoring of dietary intake targets.

\section{Composition}
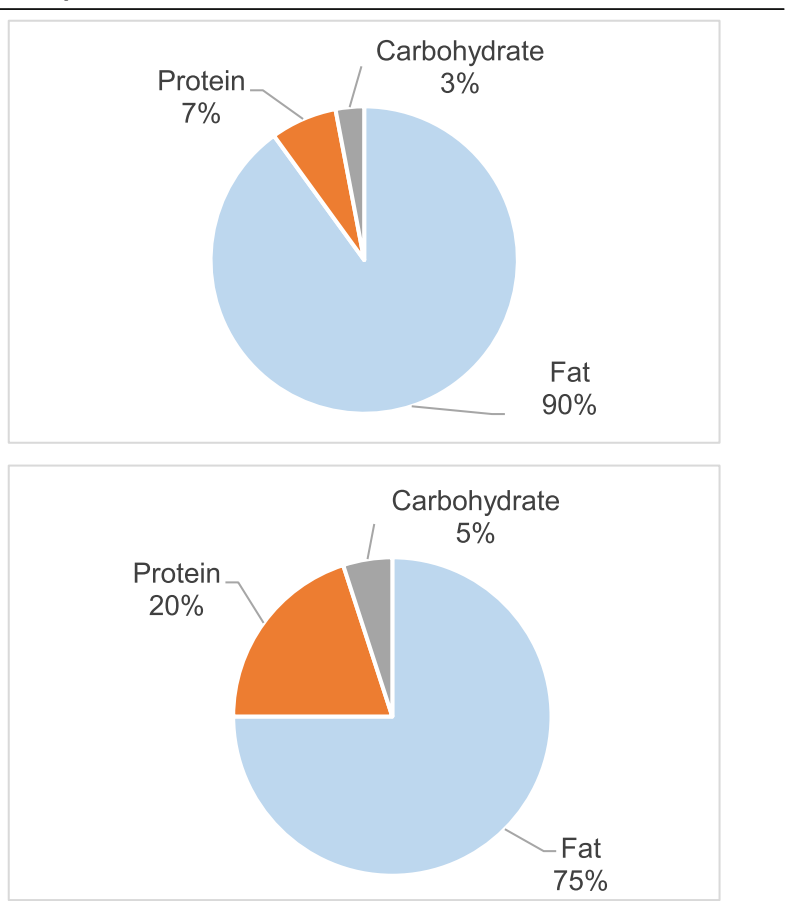

Modified Atkins ${ }^{\oplus}$ diet

Carbohydrate intake is limited to $<30 \mathrm{~g}$ per day. Liberal intake of protein, and fats are encouraged. Uses household measures and smartphone applications to monitor daily carbohydrate intake.

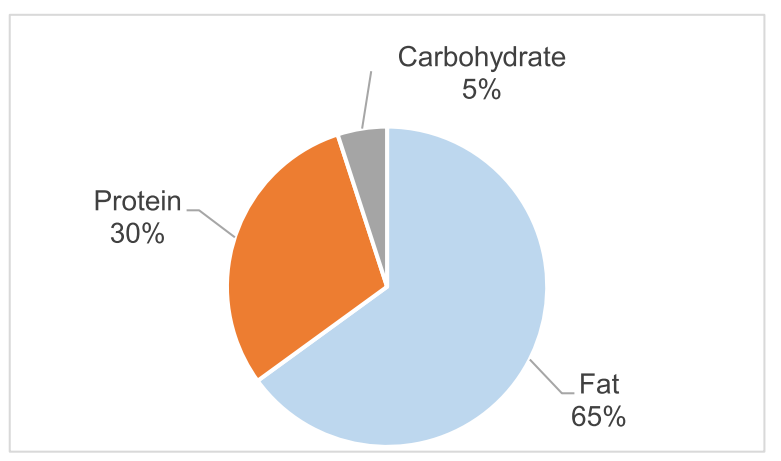

Carbohydrate intake is limited to $50 \mathrm{~g}$ per day with the glycaemic index of $<50$.

Liberal intake of protein, and fats are encouraged.

Uses household measures and smartphone applications to monitor daily carbohydrate intake Index Diet
Low Glycaemic 
Table 1 Overview of dietary therapy for epilepsy prescription types (Continued)

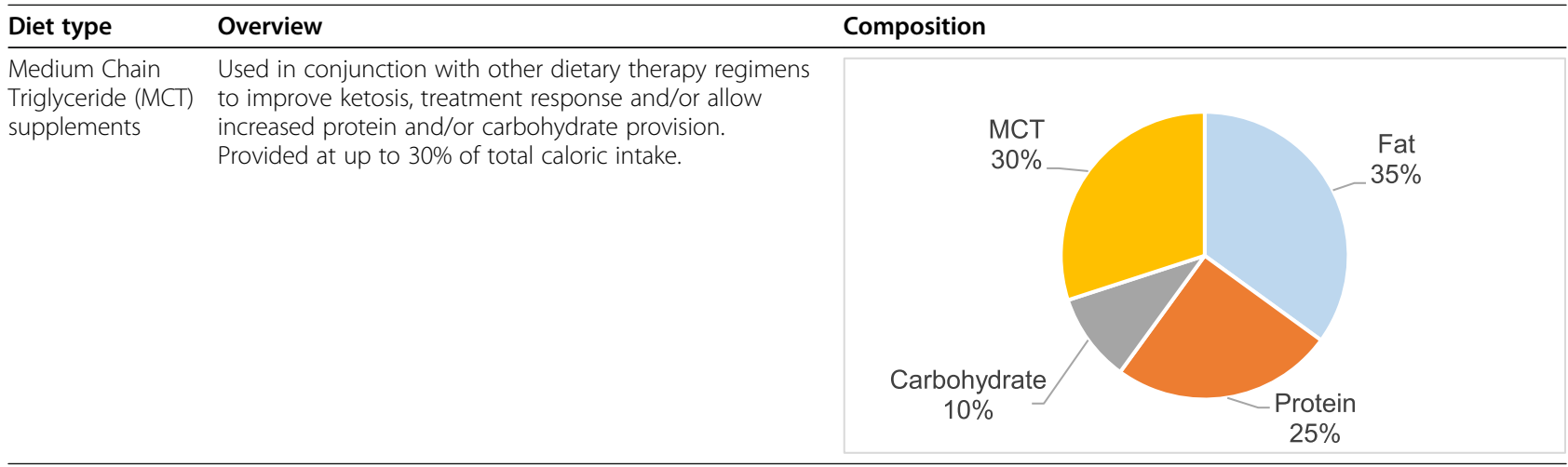

advantages over other treatment options. However, highly restrictive diets in the older adults may increase the risk of the development of malnutrition and negatively affect quality of life [19]. Additionally, the risk of complications of cardiovascular disease also require consideration. Further research is needed to evaluate the risk versus benefit of dietary therapy for epilepsy in this patient population.

\section{Selection of types of dietary therapy}

Over the past two decades, there have been a number of variations of the classical ketogenic diet to make these more feasible in adults, including the modified ketogenic, modified Atkin's, low glycaemic index and medium chain triglyceride diets used in epilepsy treatment (Table 1). To date, no head-to-head evaluation trials comparing the different dietary regimens in adults has been conducted. A more pragmatic approach may be taken in the clinical setting, evaluating the patients' baseline nutrition knowledge, level of commitment to dietary therapy and lifestyle factors when deciding on the appropriate dietary therapy. In addition, patients may transition from one diet regimen to another. For example, when first commencing on dietary therapy, a less restrictive option such as the low glycaemic index diet may first be instituted, then subsequently the patient may transition to a modified ketogenic diet. Similarly, if a patient has had a good response to the modified ketogenic diet, but was experiencing adverse effects, such as gastrointestinal intolerance, unintentional weight loss or maintaining adherence, a trial of transition to a less restrictive diet option may be considered.

\section{Diet initiation}

At the initial consultation, the dietitian in consultation with the neurologist will evaluate a patient's suitability for dietary therapy, recommend an appropriate diet prescription and request appropriate investigations (see Table 2). On commencement of dietary therapy for epilepsy, consideration should be made on the expected duration of dietary treatment for assessment of efficacy. In general, the patient should aim to maintain their recommended diet for a minimum of 3 months to assess tolerability and efficacy.

The dietitian should provide nutrition education and counselling and advise on nutrition, vitamin and mineral supplementation, in particular b-group vitamins, calcium, vitamin D and selenium [20]. Carnitine is essential in the metabolism of fatty acids and valproic acid. Patients receiving valproic acid concurrently with a high fat diet are at higher risk of carnitine deficiency. Carnitine deficiency may in turn result in ineffective metabolism of valproic acid and fatty acids and may lead to cardiomyopathy, elevated ammonia and hyperlipidaemia. Prophylactic oral levocarnitine supplementation should be given to prevent deficiency commencing at a minimum of $10 \mathrm{mg} / \mathrm{kg} /$ day. Levocarnitine dosage can be increased to a maximum dose of $3000 \mathrm{mg}$ per day if there is suspected or confirmed deficiency, elevated blood lipids and/or elevated ammonia levels [21, 22]. Patients receiving carbonic anhydrase inhibitors such as zonisamide and topiramate, may be at higher risk of kidney stones and should be monitored appropriately. Treatment of metabolic acidosis with potassium citrate may prevent the formation of kidney stones [23].

\section{Monitoring of dietary therapy}

At each follow-up visit the dietary prescription, tolerability, treatment efficacy and side-effects should be evaluated and the results of the monitoring investigations reviewed (see Table 2). Decisions to change dietary prescription and management of adverse effects should be made in collaboration with the patient, dietitian and neurologist.

The most common reported adverse effects for adults receiving dietary therapy have been gastrointestinal disturbance, including constipation, diarrhoea, nausea and vomiting [7, 9]. Constipation can be initially managed 
Table 2 Recommended monitoring investigations for adults while receiving dietary therapy for epilepsy [9]

\begin{tabular}{|c|c|c|}
\hline Investigation & Parameter & Frequency \\
\hline Nutrition assessment & $\begin{array}{l}\text { Mandatory } \\
\text { Height } \\
\text { Weight } \\
\text { Dietary intake } \\
\text { Side effects }\end{array}$ & $\begin{array}{l}\text { Baseline } \\
\text { Each clinic visit }\end{array}$ \\
\hline \multirow[t]{4}{*}{ Pathology } & $\begin{array}{l}\text { Mandatory } \\
\text { Urea and electrolytes } \\
\text { Liver function tests } \\
\text { Full blood examination } \\
\text { Blood urea nitrogen } \\
\text { Fasting lipid profile } \\
\text { Fasting glucose }\end{array}$ & $\begin{array}{l}\text { Baseline } \\
\text { Every 3-6 months }\end{array}$ \\
\hline & $\begin{array}{l}\text { Mandatory } \\
\text { Carnitine (if on valproate) } \\
\text { Vitamins \& mineral levels: vitamin D, vitamin B12, } \\
\text { folate, iron studies, zinc, Selenium }\end{array}$ & $\begin{array}{l}\text { Baseline } \\
\text { Every } 6-12 \text { months }\end{array}$ \\
\hline & $\begin{array}{l}\text { As clinically indicated } \\
\text { Ammonia } \\
\text { Plasma amino acids } \\
\text { Serum beta-hydroxy-butyrate } \\
\text { HbA1c } \\
\text { Drug levels } \\
\text { Blood ketone levels } \\
\text { Blood glucose levels }\end{array}$ & As required \\
\hline & $\begin{array}{l}\text { Urinalysis } \\
\text { Urine organic acids } \\
\text { Urine creatine calcium ratio } \\
\text { Urine ketone levels }\end{array}$ & As required \\
\hline Other investigations & $\begin{array}{l}\text { Electroencephalogram } \\
\text { Electrocardiogram } \\
\text { Lumbar puncture } \\
\text { Radiological imaging } \\
\text { Renal tract ultrasound } \\
\text { Bone density testing }\end{array}$ & As required \\
\hline
\end{tabular}

with dietary manipulation, ensuring adequate fibre and fluid intake. Laxatives may be required if constipation persists. Smaller and more frequent meals and snacks may assist with management of nausea, vomiting and diarrhoea. If fat malabsorption is suspected, introduction of medium chain triglycerides may be beneficial. Dyslipidaemia may occur initially when commencing dietary therapy for epilepsy, however in the majority of cases the levels return to baseline by 12 months. Persistent hyperlipidaemia can be managed by increasing the ratio of mono- and poly-unsaturated fats, in particular omega-3 fatty acids and reducing saturated fats in the diet [16].

Similar to anti-seizure medications, treatment efficacy of dietary therapy for epilepsy is usually defined as $>50 \%$ reduction in seizure frequency from baseline [24]. However, individualised assessment of treatment efficacy should also be considered. Examples of this may include reduction in hospital admissions, reduction in convulsive seizures, reduction in drug burden, shorter duration, intensity or recovery period of seizures, improvement in mood and/or improvement in cardiovascular disease risk factors.
Concurrent reduction in anti-seizure medications and liberalisation of dietary prescription should be avoided. If relevant, advice on the implication of medication and diet changes on driving restrictions should be provided in accordance with the local driving guidelines.

\section{Duration of dietary therapy}

With the exception of patients with glucose-transporter1-deficiency syndrome and pyruvate dehydrogenase deficiency, where dietary treatment is lifelong, it is common in paediatric practice to discontinue diet after 2 years [16]. In adult patients, who are seizure-free, it may be acceptable to consider the same two-year period for diet weaning. However, in adults who have responded to dietary therapy, but continue to have seizures and diet is well tolerated without adverse effects, it may be reasonable to continue diet long-term.

\section{Discontinuation of dietary therapy}

A weaning schedule should be prepared in consultation with the patient, dietitian and neurologist. The weaning schedule includes a gradual reintroduction of carbohydrate and reduction of fats the diet. Rapid reintroduction 
of carbohydrate may result in breakthrough seizures. There is high variability in diet weaning protocols between centres, from immediate cessation to gradual reduction over greater than 3 months [9]. The diet prescription, treatment duration, efficacy, patient adherence and adverse effects are all factors that influence the down titration schedule. In patients where dietary therapy has been ineffective, of short duration (i.e., less than 6 months) and/or presence of serious adverse effects, transition to a regular diet may occur more rapidly. In contrast, diet weaning may occur more gradually in patients with improved seizure control or on a longer duration (i.e., more than 1 year) of dietary therapy.

\section{Provision of dietary therapy}

Dietary therapy is a well-established treatment in paediatric epilepsy, however the practice has not been widely translated into adult care. In a recent international survey of neurology care providers only $17 \%$ of respondents stated dietary therapy for epilepsy was a "very" or "extremely" accepted treatment in adults compared to $84 \%$ in children [25]. Adult neurologists and dietitians may lack adequate exposure and training in dietary therapy for epilepsy, leading to reduced use. Internationally, there are few dedicated adult dietary therapy for epilepsy services $[9,26]$. It is particularly problematic for children transitioning from paediatric to adult care when an appropriate adult dietary service is not available. In this situation, adults may have to remain under paediatric services or cease dietary therapy. Moreover, there may be a reluctance to offer dietary therapy to adolescents due to inability to continue care into adulthood.

Despite there being similarities in the way dietary therapy is provided to children and adults with epilepsy, the high attrition rate in adult trials may be of concern to adult neurologists when recommending dietary therapy [7]. Development of dietary regimens, specific to the nutritional needs of adults including dietary advice tailored to the individual's preferences may be beneficial to improve the acceptance of dietary therapy. In addition, frequent access to a specialist dietitian, up-to-date resources, adequate health insurance coverage, food subsidies and patient peer support may also aid in improving dietary therapy adherence for adults.

\section{Conclusion}

Diet is an underutilised treatment for adults with drug resistant epilepsy. Inclusion of dietary therapy for epilepsy curriculum should be included as part of training for adult neurologists and dietitians providing epilepsy care. In addition, an expansion of the current level is needed to ensure adults with epilepsy have sufficient access to specialist dietary therapy services. Future research should aim to address the specific nutrition and psychosocial needs of adults for maintaining dietary therapy for epilepsy.

\section{Abbreviation \\ MCT: Medium Chain Triglyceride}

\section{Acknowledgements}

Not applicable.

\section{Authors' contributions}

NK conceptualised the manuscript idea and drafted the initial manuscript; JPN, PK and TOB revised the manuscript for intellectual content. All authors read and approved the final manuscript.

Funding

The authors received no financial support for this study.

Availability of data and materials

Not applicable.

\section{Declarations}

Ethics approval and consent to participate

Not applicable.

Consent for publication

Not applicable.

\section{Competing interests}

NK and J-PN declare no competing interests. PK is supported by a Medical Research Future Fund Fellowship (MRF1136427). He/his institution has received speaker or consultancy fees and/or research grants from Biscayne, Eisai, GW Pharmaceuticals, LivaNova, Novartis, UCB Pharma and Zynerba. TOB's institution has received research grant funding from the Australian Government NHMRC and the US Government NINDS, and commercial clinical trial and research funding from Eisai, UCB, Zynerba, Anavex and Biogen Pharma. Author TOB and PK are the member of the Editorial Board for Acta Epileptologica, who were not involved in the journal's review of, or decisions related to this manuscript.

\section{Author details}

${ }^{1}$ Department of Nutrition and Dietetics, Alfred Hospital, 55 Commercial Road, Melbourne, VIC 3004, Australia. ${ }^{2}$ Department of Allied Health (Clinical Nutrition), Royal Melbourne Hospital, Parkville, Australia. ${ }^{3}$ Departments of Neurosciences and Neurology, Alfred Hospital and Monash University, Melbourne, Australia. ${ }^{4}$ Departments of Medicine and Neurology, Royal Melbourne Hospital, University of Melbourne, Melbourne, Australia. ${ }^{5}$ Chongqing Key Laboratory of Neurology, The First Affiliated Hospital, Chongqing Medical University, Chongqing, China.

Received: 22 June 2021 Accepted: 30 June 2021

Published online: 30 July 2021

\section{References}

1. ILAE/IBE/WHO. Bringing Epilepsy out of the Shadows: Global Campaign against Epilepsy. 2001.

2. Scheffer IE, Berkovic S, Capovilla G, Connolly MB, French J, Guilhoto L, et al. ILAE classification of the epilepsies: position paper of the ILAE Commission for Classification and Terminology. Epilepsia. 2017;58(4):512-21. https://doi. org/10.1111/epi.13709.

3. Kwan P, Brodie MJ. Early identification of refractory epilespy. N Engl J Med. 2000;342(5):314-9. https://doi.org/10.1056/NEJM200002033420503.

4. Chen Z, Brodie MJ, Liew D, Kwan P. Treatment Outcomes in Patients with Newly Diagnosed Epilepsy Treated With Established and New Antiepileptic Drugs. JAMA Neurol. 2017; Available from: http://archneur.jamanetwork. com/article.aspx?doi=10.1001/jamaneurol.2017.3949.

5. Gaitatzis A. Life expectancy in people with newly diagnosed epilepsy. Brain. 2004;127(11):2427-32 [cited 2015 Oct 12]. Available from: http://www.brain. oupjournals.org/cgi/doi/10.1093/brain/awh267. 
6. Kwan P, Schachter SC, Brodie MJ. Drug-Resistant Epilepsy. N Engl J Med. 2011;365(10):919-26 Available from: http://www.nejm.org/doi/full/10.1056/ NEJMra1004418

7. Liu H, Yang Y, Wang Y, Tang H, Zhang F, Zhang Y, et al. Ketogenic diet for treatment of intractable epilepsy in adults: a meta-analysis of observational studies. Epilepsia Open. 2018;3(1):9-17 Available from: http://doi.wiley.com/1 0.1002/epi4.12098

8. Martin-McGill K, Jackson C, Bresnahan R, Levy R, Cooper P. Ketogenic diets for drug-resistant epilepsy ( Review ). Cochrane Database Syst Rev. 2018;11: Art. No:CD001903.

9. Cervenka MC, Wood S, Bagary M, Balabanov A, Bercovici E, Brown M$\mathrm{G}$, et al. International recommendations for the Management of Adults Treated with ketogenic diet therapies. Neurol Clin Pract. 2020: 10.1212/CPJ.0000000000001007. https://doi.org/10.1212/CPJ. 0000000000001007

10. Neal EG, Chaffe H, Schwartz RH, Lawson MS, Edwards N, Fitzsimmons G, et al. The ketogenic diet for the treatment of childhood epilepsy: a randomised controlled trial. Lancet Neurol. 2008;7(6):500-6 [cited 2013 Aug 25]. Available from: http://www.ncbi.nlm.nih.gov/pubmed/18456557.

11. Kaul N, Laing J, Nicolo J-P, Nation J, Kwan P, O'Brien TJ. Practical considerations for ketogenic diet in adults with super refractory status epilepticus. Neurol Clin Pract. 2020. https://doi.org/10.1212/CPJ. 0000000000001009

12. Martin-McGill KJ, Bresnahan R, Levy RG, Cooper PN. Ketogenic diets for drug-resistant epilepsy. Cochrane Database of Systematic Reviews 202(6): CD001903. https://doi.org/10.1002/14651858.CD001903.pub5.

13. MCDonald TJW, Ratchford EV, Henry-Barron BJ, Kossoff EH, Cervenka MC. Impact of the modified Atkins diet on cardiovascular health in adults with epilepsy. Epilepsy Behav. 2018;79(2018):82-6 Available from: https://doi. org/10.1016/j.yebeh.2017.10.035.

14. Conover ZR, Talai A, Klockau KS, Ing RJ, Chatterjee D. Perioperative Management of Children on ketogenic dietary therapies. Anesth Analg. 2020;131(6):1872-82. https://doi.org/10.1213/ANE.0000000000005018.

15. Klepper J, Akman C, Armeno M, Auvin S, Cervenka M, Cross HJ, et al. Glut1 deficiency syndrome (Glut1DS): state of the art in 2020 and recommendations of the international Glut1DS study group. Epilepsia Open. 2020;5(3):354-65. https://doi.org/10.1002/epi4.12414.

16. Kossoff EH, Zupec-Kania BA, Auvin S, Ballaban-Gil KR, Christina Bergqvist AG, Blackford R, et al. Optimal clinical management of children receiving dietary therapies for epilepsy: updated recommendations of the international ketogenic diet study group. Epilepsia Open. 2018;3(2):175-92. https://doi. org/10.1002/epi4.12225.

17. Sussman D, van Eede M, Wong MD, Adamson SL, Henkelman M. Effects of a ketogenic diet during pregnancy on embryonic growth in the mouse. BMC Pregnancy Childbirth. 2013;13(1). https://doi.org/10.1186/1471-2393-13-109.

18. Sussman D, Ellegood J, Henkelman M. A gestational ketogenic diet alters maternal metabolic status as well as offspring physiological growth and brain structure in the neonatal mouse. BMC Pregnancy Childbirth. 2013;29:13

19. Zeanandin G, Molato O, Le Duff F, Guérin O, Hébuterne X, Schneider SM. Impact of restrictive diets on the risk of undernutrition in a free-living elderly population. Clin Nutr. 2012;31(1):69-73. https://doi.org/10.1016/j. clnu.2011.08.007

20. Neal EG, Zupec-Kania B, Pfeifer HH. Carnitine, nutritional supplementation and discontinuation of ketogenic diet therapies. Epilepsy Res. 2012;100(3): 267-71 Available from: https://doi.org/10.1016/j.eplepsyres.2012.04.021.

21. De Vivo DC, Bohan TP, Coulter DL, Dreifuss FE, Greenwood RS, Nordli DR Jr, et al. L-carnitine supplementation in childhood epilepsy: current perspectives. Epilepsia. 1998;39(11):1216-25. Available from: http://dialog proquest.com/professional/docview/689040277?accountid=158040. https:// doi.org/10.1111/j.1528-1157.1998.tb01315.x.

22. Lheureux PER, Penaloza A, Zahir S, Gris M. Science review: Carnitine in the treatment of valproic acid-induced toxicity - What is the evidence? Crit Care. 2005;9:431-40

23. Bjurulf B, Magnus $P$, Hallböök T, Strømme P. Potassium citrate and metabolic acidosis in children with epilepsy on the ketogenic diet: a prospective controlled study. Dev Med Child Neurol. 2020;62(1):57-61. https://doi.org/10.1111/dmcn.14393

24. Mohanraj R, Brodie MJ. Measuring the efficacy of antiepileptic drugs. Seizure. 2004;1311(03):187-90.
25. Seaborg K, Wang X, Olson C, Felton EA. Pediatric to adult transitions of ketogenic dietary therapy for epilepsy. J Child Neurol. 2020;35(13):896-900. https://doi.org/10.1177/0883073820938587.

26. Whiteley VJ, Martin-McGill KJ, Carroll JH, Taylor H, Schoeler NE. Nice to know: impact of NICE guidelines on ketogenic diet services nationwide. J Hum Nutr Diet. 2020;33(1):98-105. https://doi.org/10.1111/jhn.12697.
Ready to submit your research? Choose BMC and benefit from:

- fast, convenient online submission

- thorough peer review by experienced researchers in your field

- rapid publication on acceptance

- support for research data, including large and complex data types

- gold Open Access which fosters wider collaboration and increased citations

- maximum visibility for your research: over $100 \mathrm{M}$ website views per year

At BMC, research is always in progress.

Learn more biomedcentral.com/submissions 